\title{
EXPERIMENTAL SETUP FOR TESTING ROTARY MR DAMPERS WITH ENERGY HARVESTING CAPABILITY
}

\author{
Bogdan SAPIŃSKI", Marcin WĘGRZYNOWSKI* \\ *AGH University of Science and Technology, Faculty of Mechanical Engineering and Robotics, Department of Process Control, \\ Al. Mickiewicza 30, 30-059 Kraków, Poland \\ deep@agh.edu.pl, mweg@agh.edu.pl
}

\begin{abstract}
The experimental setup has been developed for laboratory testing of electromechanical energy transducers and rotary magnetorheological (MR) dampers. The design objectives are outlined and the parameters of the key elements of the setup are summarised. The structure of the mechanical and measurement and control systems is presented. Results of functional testing of a newly developed transducer and a MR rotary damper are summarised.
\end{abstract}

Key words: MR Rotary Damper, Experimental Setup, Energy Harvesting

\section{INTRODUCTION}

Conventional semi-active vibration reduction systems require an external source of energy. Recently a great deal of attention has been given to semi-active self-powered systems utilising the recovered energy of vibrations (Wang et al., 2009, 2010; Sapiński, 2011; Zhu et al., 2012; Wang and Bai, 2013; Li et al., 2013). Such systems incorporate electromechanical transducers which convert the mechanical into electrical energy.

The experimental setup was constructed for testing the main subassemblies of semi-active vibration reduction systems capable of recovering the energy of rotating motion which are an electromechanical transducer and a MR damper. Mechanical energy is generated by a rotating object (a disk in a flywheel, powered by an electric motor), the energy conversion is effected through the use of a rotary electromechanical transducer whilst electric energy (load) is taken up by a rotary MR damper. The functional testing of the setup is summarised, testing was done on a newly developed electromechanical transducer (Sapiński and Krupa, 2011) and a MR damper (Sapiński and Szydło, 2013).

An experimental setup for similar tests is described in works (Vavreck and Ho, 2005; Młot, 2007; An and Kwon, 2003; Sapiński and Bydłoń, 2002). The experimental setup for testing the characteristics of a rotary MR damper under the torsion is presented in Vavreck and Ho (2005). The work (Młot, 2007) investigates the setup for testing electric motors and electromechanical transducers, while An and Kwon (2003) focuses on testing of power elements filled with MR fluid, including rotary MR dampers. The work (Sapiński and Krupa, 2011) explores the applications of MR dampers to control rotational speed.

\section{EXPERIMENTAL SETUP}

Underlying the structure of the experimental setup are the design objectives and requirements. Utmost care was taken to ensure easy adaptability of the setup configuration, to enable the testing of transducers, dampers and MR dampers with the energy recovery capability without the needs of major restructuring and to implement the rotary motion in both directions, at the maximal speed $\omega_{\max }=600$ [rpm]. Finally, the serial structure was adopted in which all elements are configured coaxially, as shown in the schematic diagram Fig. 1, revealing the most expanded version, incorporating an MR damper with the energy recovery capability (MR damper connected with an electromechanical energy transducer). The internal damping in the shafts, pivots and couplings is neglected. The operational characteristics of the driving motor BSM90N (manufactured by BALDOR (http://www.baldor.com/) and of the electromagnetic transducer are assumed to be known beforehand. Basing on the manufacturer's data on the rotary MR damper RD-2087-01 (http://openi.nlm.nih.gov) supplied by the LORD Co., the variability range of torque is assumed $0.4-10$ $[\mathrm{Nm}]$, the maximal speed $\omega_{\max }=600[\mathrm{rpm}]$. Torsional rigidity (elasticity constants) of couplings of the Toolflex (http://www.ktr.com/ de/home.htm) type is taken into account. The manufacturers' specifications and calculation data on the designed assemblies of the driving system were utilised to find the parameters of the test facility (Tab. 1).

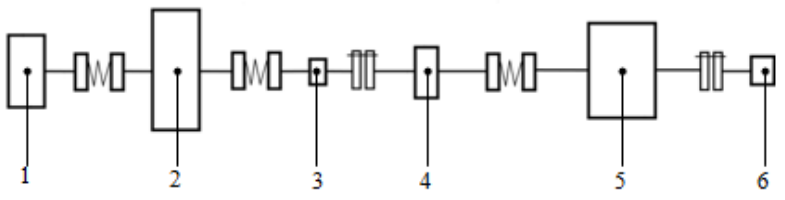

Fig. 1. Experimental setup: 1 - electric motor; 2 - flywheel;

3 - torque meter; 4 - MR damper;

5 - electromechanical transducer; 6 - encoder

Bridle joints are provided at most critical points in consideration of the variable driving torque. This solution enables the transmission of the nominal stationary driving torque and of the acting overloading moment whose instantaneous value may double. As the measuring system in the torque meter are particularly sensitive to overloading, a torque coupling is provided, set on a bridle joint, between the torque meter and the MR damper.

All elements are fixed on the structure made of aluminium profiles (Fig. 2). This construction allows a prompt modification of the setup, at the same time retaining the coaxial array of its constituent elements. 
Tab. 1. Parameters of the test facility

\begin{tabular}{|c|c|c|}
\hline \multirow{2}{*}{ Element } & \multicolumn{2}{|c|}{ Parameter } \\
\cline { 2 - 3 } Motor & Name & Value \\
\cline { 2 - 3 } & Nominal torque & $6[\mathrm{~N} \cdot \mathrm{m}]$ \\
\hline \multirow{2}{*}{ Flywheel disk } & Mass moment of inertia & $50 \cdot 10-4[\mathrm{~kg} \cdot \mathrm{cm} 2]$ \\
\hline \multirow{2}{*}{ Torque meter } & Mass moment of inertia & $0.1 \cdot 10-4[\mathrm{~kg} \cdot \mathrm{m} 2]$ \\
\cline { 2 - 3 } & Torsional rigidity & $417.4[\mathrm{~N} \cdot \mathrm{m} / \mathrm{rad}]$ \\
\hline \multirow{2}{*}{ MR damper } & Mass moment of inertia & $0.76 \cdot 10-4[\mathrm{~kg} \cdot \mathrm{m} 2]$ \\
\cline { 2 - 3 } & Torsional rigidity & $3762[\mathrm{~N} \cdot \mathrm{m} / \mathrm{rad}]$ \\
\hline \multirow{2}{*}{ Transducer } & Mass moment of inertia & $20 \cdot 10-4[\mathrm{~kg} \cdot \mathrm{m} 2]$ \\
\cline { 2 - 3 } & $\begin{array}{r}\text { Torsional rigidity of the } \\
\text { shaft }\end{array}$ & $30000[\mathrm{~N} \cdot \mathrm{m} / \mathrm{rad}]$ \\
\hline \multirow{2}{*}{ Encoder } & Mass moment of inertia & $0.05 \cdot 10-4[\mathrm{~kg} \cdot \mathrm{m} 2]$ \\
\hline
\end{tabular}

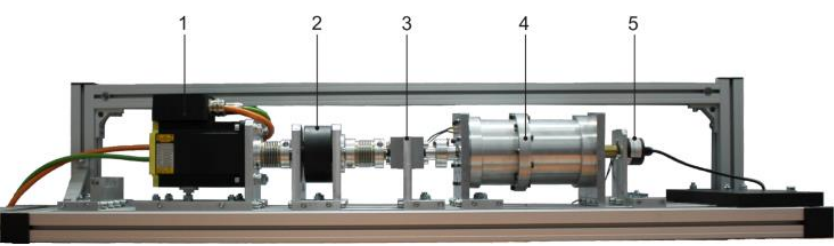

Fig. 2. View of the experimental setup: 1 - motor, 2 - flywheel,

3 - torque meter; 4 - MR damper with energy recovery capability, 5 - encoder

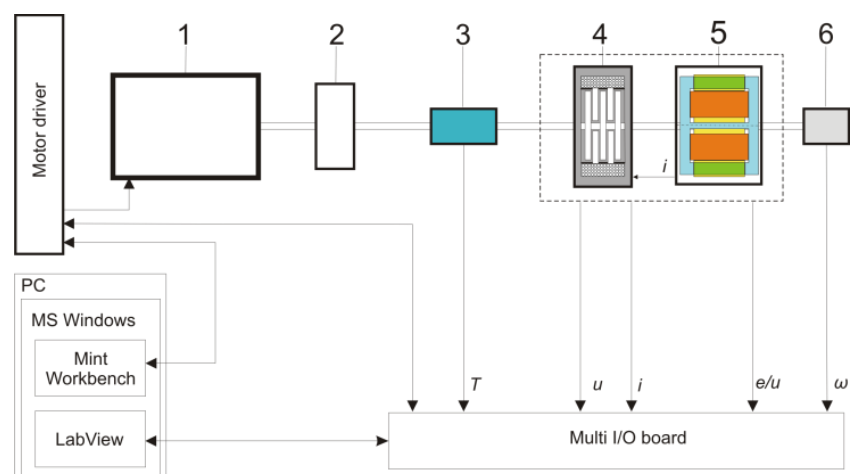

Fig. 3. Schematic diagram of the measurement and control system: 1 - motor, 2 - flywheel, 3 - torque meter, 4 - MR damper, 5 - electromechanical transducer, 6 - encoder

The schematic diagram of the measurement and control system is shown in Fig. 3. The system comprises a control box CompacDAQ (National Instruments) connected to a computer via a USB port, an impulse feeder and the drive element MINT Drive II (controlled by the Mint Workbench software), controlling the electric motor (manufactured by Baldor). The LabView 2010 installed on a PC operates under MS Windows. Analogue modules (N19227 (http://www.ni.com/pdf/manuals/374068f.pdf), N19205 (http://www.ni.com/pdf/manuals/374188d.pdf) and a digital module (NI9401 (http://www.ni.com/pdf/manuals/374068f.pdf) are installed in the control box CompacDAQ. The power drive in the motor is connected to the PC via a port RS232. Operating parameters of the motor are adjustable with the use of the Mint Workbench software (setting the controllers' parameters and the operational parameters) or using the analogue output card in the CompacDAQ box (adjustment of operational parameters).

\section{FUNCTIONAL TESTING}

Testing was done on a newly-developed electromechanical transducer and a MR damper to determine their characteristics.

In the first place the dynamic characteristic of the transducer was determined under the step voltage supplied to its coil $u(t)=0.5 \mathrm{I}(t)[\mathrm{V}]$ (Fig. 4). The time constant of the transducer coil was $0.068[\mathrm{~s}]$.

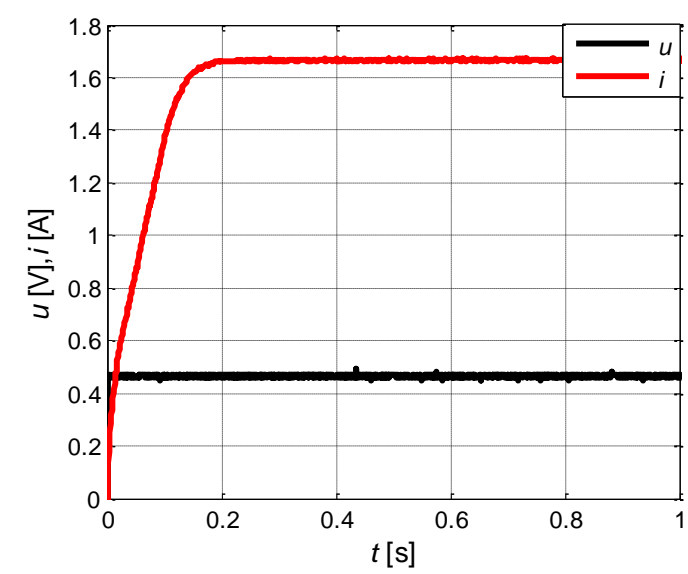

Fig. 4. Dynamic characteristic of the transducer

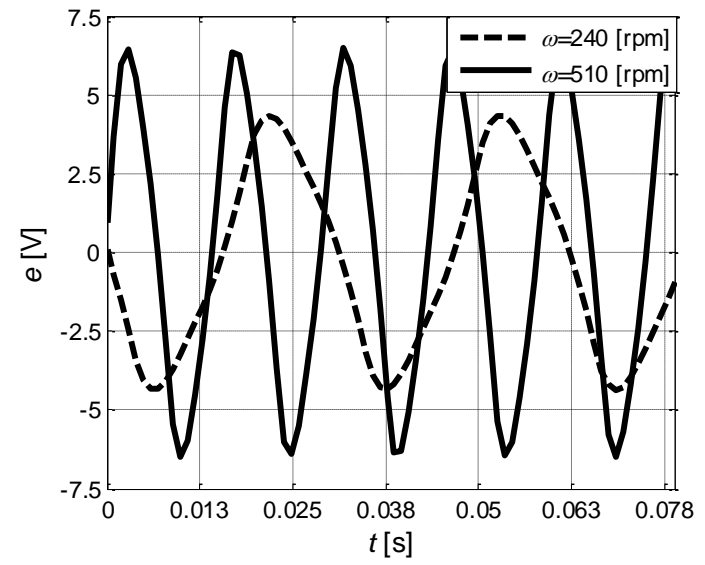

Fig. 5. Emf force $e$ in the function of time

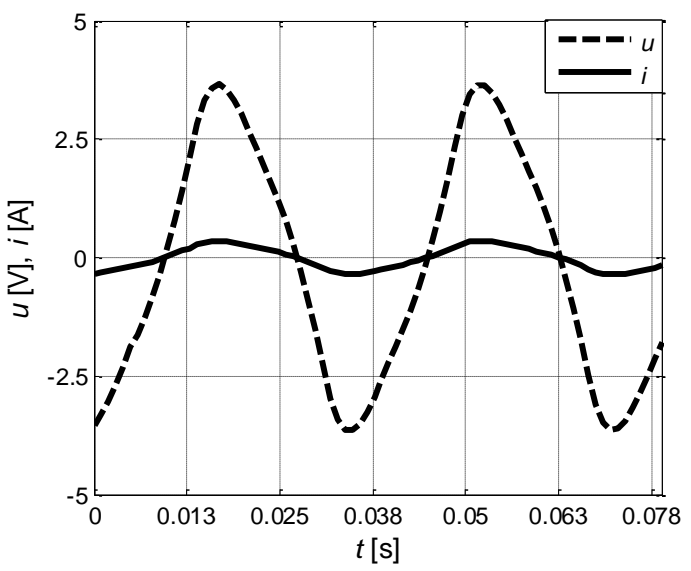

Fig. 6. Voltage $u$ and current $i$ in the function of time; resistance load 
The transducer characteristic was then determined under the idle run and under the resistance loading $(10[\Omega])$ and resistanceinduction loading (MR damper's control coil) at the rotating speed in range $\omega(0,600)$ [rpm]. The plots of emf force under the idle run are shown in Fig. 5, voltage $u$ and current $\mathrm{i}$ (under loading) at the rotational speed $\omega=240$ [rpm] are shown in Fig. 6 and 7. It appears that the electromotive force induced in the transducer coil increases with an increase in rotational speed (Fig. 5).

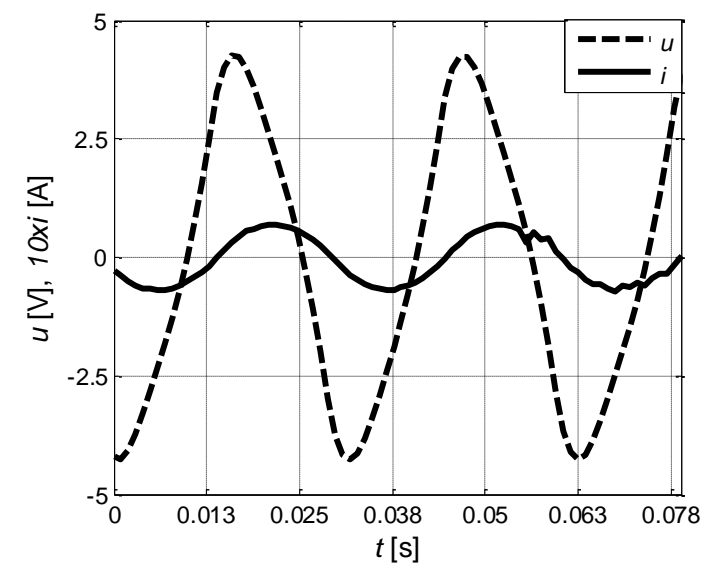

Fig. 7. Voltage $u$ and current $i$ in the function of time; resistance-induction load

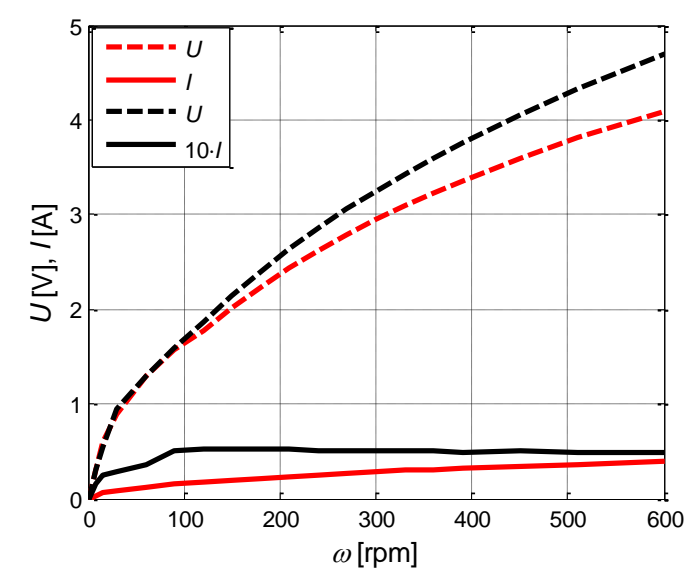

Fig. 8. Rms values of voltage and current under the resistance load and the resistance-induction load

Under the resistance load (grey line), voltage and current the transducer tends to increase with rotational speed. When the transducer is subjected to the load due to the MR damper control coil (black line), the current $i$ tends to increase linearly in the velocity range $(0,100)[\mathrm{rpm}]$. At velocities in excess of $\omega=100$ [rpm], the current reaches the level $0.05[\mathrm{~A}]$ and stabilises despite the further increase of the rotational speed (Fig. 8).

Further tests were done on a MR damper to determine its static $T(I)$ and dynamic $i(t)$ characteristics. Static characteristics were determined under the low frequency sine voltage signal applied to the coil. The dynamic characteristics of the MR damper were obtained under the step voltage changes $u(t)=16 \cdot \mid(t)[\mathrm{V}]$ in the control coil (Fig. 9). The time constant of the control coil in the MR damper is 0.052 [s].

Static characteristics of the damper for the unipolar powersupply of the control coil were showed in Fig. 10. It is readily apparent (Fig. 10) that the static characteristics of the MR damper exhibits the hysteresis associated with the properties of its component materials. The maximal ambiguity error for the MR damper is equal to $22.5 \%$ of the maximal torque generated by the damper. The initial torque $(0.16[\mathrm{Nm}])$ is associated with viscous friction and magnetic residues in the damper housing and disks.

On the basis of characteristics of the investigated transducer and the damper it appears that the MR damper with the energy recovery capability is able to generate the maximal torque $0.25[\mathrm{Nm}]$.

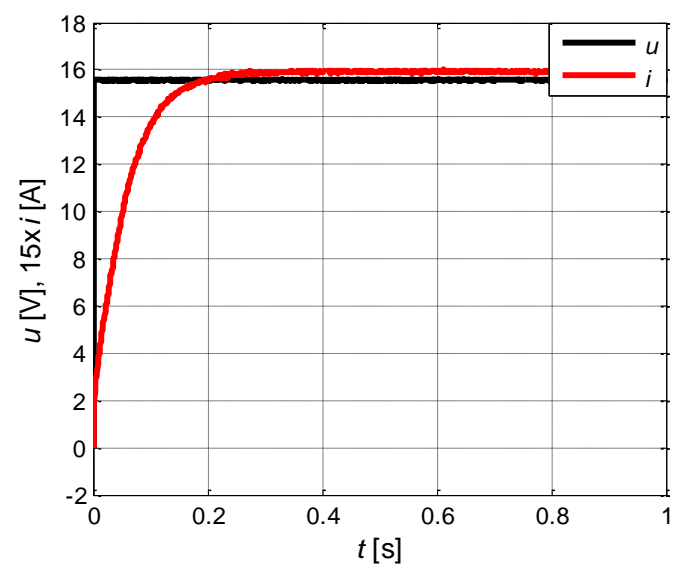

Fig. 9. Dynamic characteristics of the MR damper

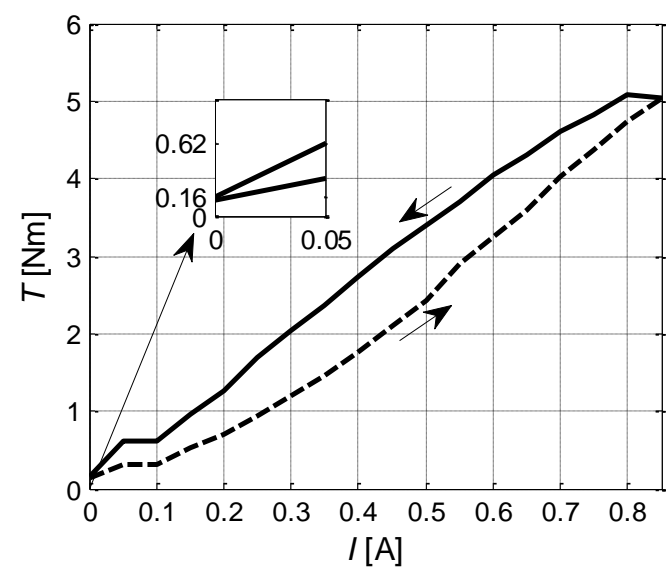

Fig. 10. Static characteristics of the MR damper

\section{SUMMARY}

The laboratory setup has been designed for testing the MR dampers with the energy recovery capability. The design objectives and the structure of the test facility is outlined, results of testing done on a newly developed rotational transducer and a MR damper are summarised.

High rigidity of the test facility, and carefully selected bearings and couplings help maintain the coaxial array of its all components, at the same time making it modifications easy. Extensive tests revealed that the setup performs well both in the low and high range of rotational speed. Results evidence the correct performance of the measurement and control system, which proves to be insensitive to disruptions and its modular structure makes it easily adjustable and modifiable. 
This experimental setup is intended for use for research and teaching in the Laboratory of Adaptronics in the Department of Process Control of AGH-UST.

\section{REFERENCES}

1. An J., Kwon D. S. (2003), Modeling of a Magnetorheological Actuator Including Magnetic Hysteresis, http://citeseerx.ist.psu.edu/ viewdoc/download?doi=10.1.1.101.4352\&rep=rep1\&type=pdf.

2. Li Z., Zhuo L., Luhrs G., Lin L., Qin Y. (2013), Electromagnetic Energy-Harvesting Shock Absorbers: Design, Modeling and Road Tests. IEEE Transactions on Vehicular Technology, Vol. 62, no.3, 1065-1074.

3. Młot A. (2007), Structural pulsation dampening methods of the electromechanical torque in a brushless DC motor with permanent magnets, PhD thesis. Opole University of Technology, Faculty of electrical engineering, Automatic control and informatics. (in Polish)

4. Sapiński B., Krupa S. (2011), Rotary transducer of mechanical energy into electrical energy, Application for the patent no. P-395 787. (in Polish)

5. Sapiński B. (2011), Experimental study of self-powered and sensing MR damper-based vibration control system. Smart Materials and Structures, Vol. 20, 105012.

6. Sapiński B., Bydoń S. (2002), Application of Magnetorheological Fluid Brake to Shaft Position Control in Induction Motor, Pneumatyka, Vol.3, no.34, 27-29. (in Polish)

7. Sapiński B., Szydło Z. (2013), Magnetorheological damper for torsional vibration with electromechanical rotary transducer. Application for the patent no. P-403 371 (in Polish)
8. Vavreck A. N., Ho Ch. H. (2005), Characterization of a commercial magnetorheological brake/damper in oscillatory motion, Smart Structures and Materials: Damping and Isolation, 256-267.

9. Wang Z. H., Chen, Z. Q. and Spencer, B. F. (2009), Self-powered and sensing control system based on MR damper, presentation and application, Proc. of SPIE on Sensors and Smart Structures Technologies for Civil, Mechanical, and Aerospace Systems, 7292, 729240.

10. Wang D. H., Bai X. X.(2013), A magnetorheological damper with an integrated self-powered displacement sensor. Smart Materials and Structures, Vol. 22, 075001.

11. Wang D. H., Bai X. X., Liao W. H.(2010), An integrated relative displacement self-sensing magnetorheological damper: prototyping and testing. Smart Materials and Structures, Vol.19, 105008.

12. Zhu S. Y., Shen W. A., Xu Y. L., Lee W. C.(2012), Linear electromagnetic devices for vibration damping and energy harvesting: Modeling and testing, Engineering Structures, Vol. 34, 198-212.

13. http://www.baldor.com/

14. http://openi.nlm.nih.gov/detailedresult.php?img=3251984_sensors11 $11305 f 22 \& q u e r y=$ the\&fields=all\&favor=none\&it=none\&sub=none\&uni $\mathrm{q}=0$ \&sp=none\&req=4\&simCollection=3142198 $1477-7525-9-44-$ 1\&npos $=86 \&$ prt $=3$

15. http://www.ktr.com/de/home.htm

16. http://www.ni.com/pdf/manuals/374068f.pdf

17. http://www.ni.com/pdf/manuals/374188d.pdf

18. http://www.ni.com/pdf/manuals/374068f.pdf

This research is supported by the National Centre for Research and Development under grant No. NR03-0046-10. 